\title{
Polycystic Ovary Syndrome as a systemic disease with multiple molecular pathways: a narrative review
}

\author{
Laura M. L. Carvalho ${ }^{1}$, Fernando M. dos Reis's, Ana Lucia Candido², Fernanda F. C. Nunes \\ Claudia N. Ferreir A ${ }^{3,4}$, Karina B. Gomes ${ }^{1,3}$
}

${ }^{1}$ Instituto de Ciencias Biologicas, Universidade Federal de Minas Gerais, Belo Horizonte, Minas Gerais, Brazil; ${ }^{2}$ Faculdade de Medicina, Universidade Federal de Minas Gerais, Belo Horizonte, Minas Gerais, Brazil, ${ }^{3}$ Faculdade de Farmacia, Universidade Federal de Minas Gerais, Belo Horizonte, Minas Gerais, Brazil; ${ }^{4}$ Colegio Tecnico, Universidade Federal de Minas Gerais, Belo Horizonte, Minas Gerais, Brazil

E-mail: karinabgb@gmail.com

\begin{abstract}
Polycystic Ovary Syndrome (PCOS) is characterized by hyperandrogenism, amenorrhea, and polycystic ovaries. This endocrinopathy is associated with many metabolic disorders such as dyslipidemia and insulin resistance, with increased risk of type 2 diabetes mellitus, metabolic syndrome, and cardiovascular complications. Inflammation is likely to play an important role in the promoting these metabolic imbalances, while prothrombotic and pro-oxidative mechanisms further contribute to the cardiovascular risk of these patients. The etiology of PCOS is still not fully understood, but there is evidence of genetic and environmental components. This review aims to discuss some molecular pathways associated with PCOS that could contribute to the better understanding about this syndrome. Recent evidence suggests that intrauterine exposure of female mice to an excess of anti-Müllerian hormone may induce PCOS features in their post-natal life. High cytokine levels and cytokine gene polymorphisms also appear to be associated with the pathophysiology of PCOS. Furthermore, high levels of microparticles may contribute to the altered hemostasis and enhanced inflammation in PCOS. All these mechanisms may be relevant to clarify some aspects of PCOS pathogenesis and inspire new strategies to prevent the syndrome as well as treat its symptoms and mitigate the risk of long-term complications.
\end{abstract}

Key words: polycystic ovary syndrome, pathophysiology, metabolism, inflammation, hyperandrogenism, hemostasis

Polycystic Ovary Syndrome (PCOS) is the most common endocrine disorder in women of reproductive age (Bachanek et al. 2015; Jalilian et al. 2015; Bachelot 2016; Glintborg and Andersen 2017; Papadakis et al. 2017; Reis et al. 2017). The patients usually present hyperandrogenism, amenorrhea, and polycystic ovaries (Palomba et al. 2015; Aytan et al. 2016; Carvalho et al. 2017a; Glintborg and Andersen 2017; Reis et al. 2017) but not necessarily all of these conditions, since the existence of a great phenotypic variability (Unluturk et al. 2016).
Three criteria of PCOS diagnose are available: 1990 $\mathrm{NIH}$ (National Institute of Health) and National Institute of Child Health and Human Disease criteria (NICHD); 2003 Rottersdam criteria; and the 2006 Androgen Excess Society (AES) criteria. The first one considers hyperandrogenism and ovulatory dysfunction, while the Rotterdam criteria, jointly proposed by the American Society of Reproductive Medicine (ASRM) and the European Society of Human Reproduction and Embryology (ESHRE), include two out of the three manifestations: hyperandrogenism, ovu-

Corresponding author: Karina Braga Gomes, Departamento de Analises Clinicas e Toxicologicas, Faculdade de Farmacia, Universidade Federal de Minas Gerais, Av. Antonio Carlos, 6627, Pampulha, Belo Horizonte, Minas Gerais, Brazil, zip code: 31270-901; phone/fax: +55 (31) 3409-6895/ +55 (31) 3409-6885; e-mail: karinabgb@gmail.com. 
latory dysfunction and polycystic ovaries. The AES criteria state that PCOS women should present, besides hyperandrogenism, ovarian dysfunction, polycystic ovaries or both complications (Jayasena and Franks 2014).

Women with PCOS present a higher risk of obesity (in particular the visceral phenotype), dyslipidemia, insulin resistance (IR) with compensatory hyperinsulinemia, type 2 diabetes mellitus (T2DM), metabolic syndrome and cardiovascular complications (Palomba et al. 2015; Silva et al. 2015; Azziz et al. 2016; Pavaleanu et al. 2016; Carvalho et al. 2017a; Papadakis et al. 2017; Xavier et al. 2018). Another relevant complication is infertility due to chronic anovulation (Joham et al. 2015; Glintborg and Andersen 2017) (Figure 1).

The etiology of PCOS is still not fully understood (Soter et al. 2015; Dunaif 2016), but certainly corresponds to a multifactorial disorder (Insenser and Escobar-Morreale 2013; Aytan et al. 2016). Despite the gaps in the understanding of the pathogenesis of PCOS, several associated biochemical abnormalities have been well described and inflammation is likely to play an important role in promoting these metabolic imbalances (Repaci et al. 2011; Carvalho et al. 2017a).

The recurrence of cases in the same family and studies with twins emphasize the importance of genetic factors in the pathophysiology of PCOS (KahsarMiller and Azziz 1998; Vink et al. 2006; Azziz 2008). In addition, first-degree relatives of both genders of women with PCOS are also at increased risk of presenting the metabolic disorders associated with this syndrome (Norman et al. 2007). More than 100 candidate genes have been evaluated in previous studies, most of which are related to reproductive hormones, cellular metabolism, chronic inflammation, cell proliferation, and hemostasis (Jia et al. 2012; Ruan et al. 2012; Sales et al. 2013; Zhao et al. 2016; Hosseini et al. 2017; Reddy et al. 2018). More recently, Genome

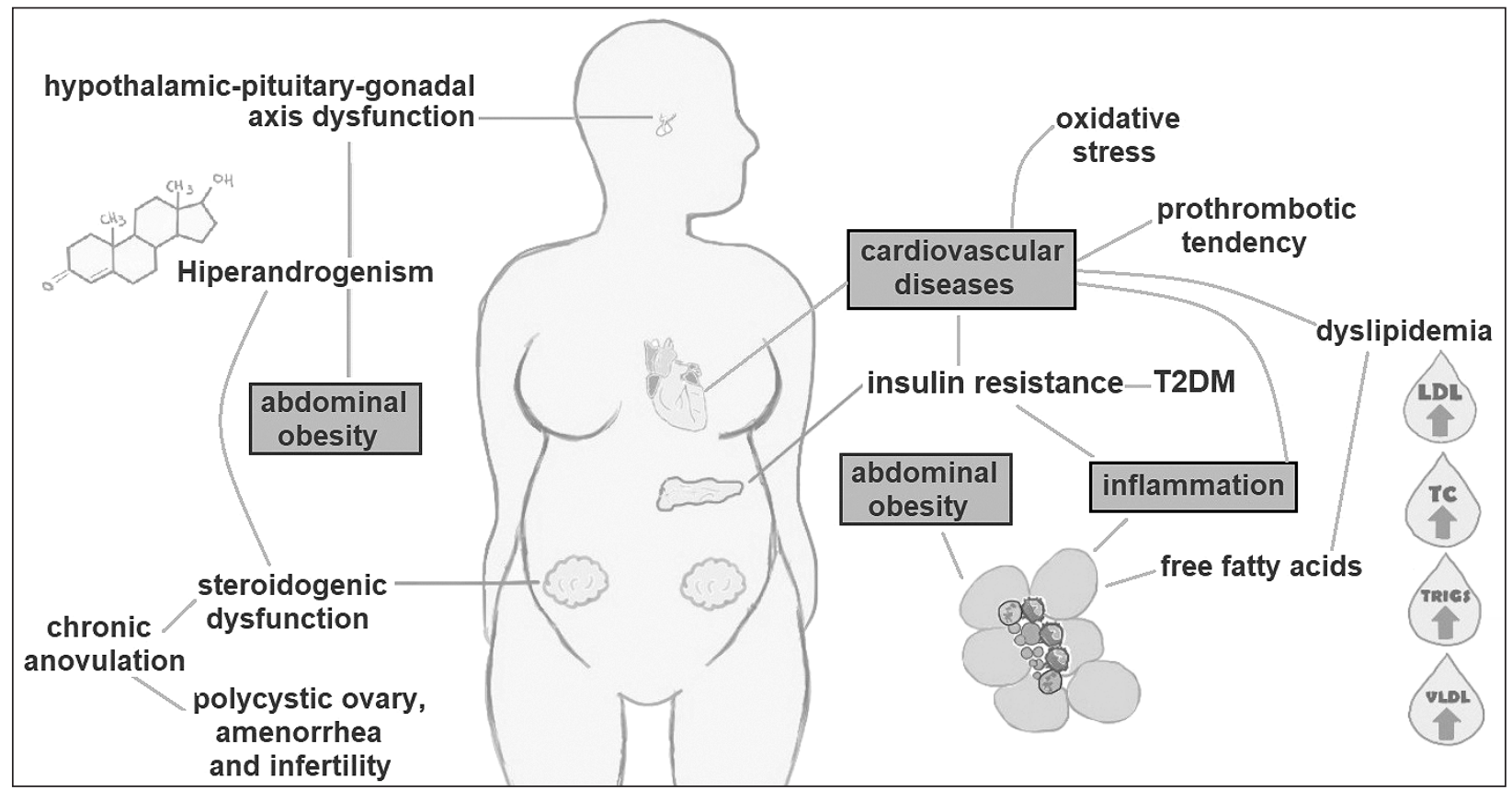

Figure 1. Important biochemical pathways involved in the pathophysiology of PCOS. Hyperandrogenism is a central feature in PCOS. Patients have a dysfunction in the hypothalamic-pituitary-gonadal axis, which influences steroidogenesis. In the ovaries, theca cells exhibit steroidogenic dysregulation that elevates circulating androgens. In addition, women with PCOS have lower levels of SHBG, which raise the level of free testosterone. Hormonal imbalance causes the follicular development to be prematurely disrupted, causing chronic anovulation, amenorrhea, polycystic ovaries and infertility. Hyperandrogenism is also associated with accumulation of fat in the abdominal region and hyperinsulinemia secondary to insulin resistance (IR). Inflammation is considered an important link between the metabolic effects of PCOS, such as IR, dyslipidemia and T2DM. Visceral obesity causes an increase in plasma levels of inflammatory mediators and the adipocytes release fatty acids by lipolysis, causing dyslipidemia. PCOS women have higher oxidative stress markers and also an imbalance between pro- and anti-coagulant mediators. Hemostatic and oxidative imbalances, combined with inflammation, IR and dyslipidemia are factors that increase cardiovascular risk in these patients. TC $=$ total cholesterol, Trigs $=$ triglycerides, $\mathrm{T} 2 \mathrm{DM}=$ type 2 diabetes mellitus. 
Wide Association Studies (GWAS) have identified other several promising genes that may be related to the syndrome (Liu et al. 2016; Zhao et al. 2016). INSR, LHCGR, FSHR, YAP1, and C9orf3 are some examples of genes highlighted by these studies based on GWAS (Liu et al. 2016).

It is also clear that environmental factors are of great importance in the development of PCOS (Norman et al. 2007; Faghfoori et al. 2017). Modifications in diet quality and weight loss improve fertility, IR, (Bagatini 2010; Faghfoori et al. 2017), dyslipidemia, and hyperandrogenism (Bagatini 2010). In addition, physical exercise brings beneficial results to the patients' health, with the reduction of IR and improvement of reproductive biomarkers such as antral follicle count and serum levels of sex steroids, gonadotropins and anti-Müllerian hormone (AMH) (Al-Eisa et al. 2017).

PCOS is a condition of high prevalence (Zhao et al. 2006; Tehrani et al. 2011; Musmar et al. 2013; Jiao et al. 2014) with an important impact on the quality of life (Palomba et al. 2015; Silva et al. 2015; Pavaleanu et al. 2016; Papadakis et al. 2017). Although it is significantly expensive for the health system, the understanding of its pathophysiology is very relevant (Azziz et al. 2005). This review aims to discuss hormonal, inflammatory, metabolic, and hemostatic profiles associated with PCOS that could contribute to the better understanding about this syndrome.

\section{Pathophysiology of PCOS}

Hyperandrogenism. An important feature in PCOS is the modification in androgenic dynamics (Morgante et al. 2015). The theca cells of women with PCOS have intrinsic steroidogenic dysregulation (Rosenfield and Ehrmann 2016), which involves the overexpression of the enzymes CYP11A, 3-HSD, and CYP17 and the Luteinizing Hormone (LH) receptor (Magoffin 2005). In the ovarian granulosa cells, estradiol is generated by aromatase conversion of theca cell-derived androgens, but the aromatase activity is altered in women with PCOS, which reduces this conversion (Chen et al. 2015). Genetic variants of the aromatase gene (CYP19) have been associated with the development of PCOS (Maliqueo et al. 2013). In addition, when analyzing the follicle morphology of women with PCOS, an internal theca hyperplasia has been observed (Magoffin 2005), which may also contribute to the elevation of androgen levels.

In vitro, insulin stimulates the production of androgens by theca cells (Nahum et al. 1995). Unlike muscle and adipose tissue, theca cells remain insulin sensitive and their response to hyperinsulinemia is a greater production of androgens (Magoffin 2005). Some studies have shown that insulin can also act as a stimulant of adrenal androgen production (Rittmaster et al. 1993; Kristiansen et al. 1997; De Leo et al. 2016). The use of insulin sensitizing drugs, such as metformin, reduces the level of circulating androgens (Morgante et al. 2015), which corroborates the hypothesis that IR plays a central role in the hyperandrogenic character of PCOS.

Another relevant finding is that the patients with PCOS (obese and non-obese) present higher activity of 5 a-reductase - an enzyme that converts testosterone to dihydrotestosterone (DHT), a more potent androgen - in skin, ovaries and liver compared to healthy controls (Jakimiuk et al. 1999; Skalba et al. 2006; Vassiliadi et al. 2009). Goodarzi et al. (2006) have shown an association between SRD5A2 gene polymorphisms that reduce the enzymatic activity of $5 \alpha$-reductase and a lower risk of PCOS. In addition, they have demonstrated that $5 \alpha$-reductase activity is closely associated with the body mass index (BMI) and fasting insulin levels in women with PCOS (Vassiliadi et al. 2009).

In PCOS women, the serum levels of sex hormone binding globulin (SHBG) tend to be decreased, which contributes to an increase in free testosterone (Nestler et al. 1991; Fan et al. 2013; Azziz et al. 2016; Deswal et al. 2018), the biologically active form of the hormone (Burtis et al. 2008). This is believed to happen because insulin inhibits SHBG production by hepatocytes, a mechanism that may be exacerbated in women with PCOS due to hyperinsulinemia (Nestler et al. 1991; Bartha et al. 2000; Azziz et al. 2016). In a cross-sectional study conducted by Seyfart and colleagues (2018), higher levels of total testosterone were associated with higher BMI in healthy women. Moreover, higher levels of SHBG were associated with lower BMI, abdominal circumference, waist to hip ratio, leptin levels and adiposity (visceral and subcutaneous adipose tissue measured by magnetic resonance imaging). Deswal et al. (2018) have analyzed 10 studies about the effects of therapeutic interventions (with inositol, metformin, oral contraceptives, rosiglitazone, omega 3 or arcabose) on SHBG levels in women with PCOS, and have observed that the increase of SHBG levels is associated to an improvement in endocrine and metabolic parameters in these women.

Hyperandrogenism may also be associated with a greater accumulation of abdominal fat in PCOS women (Escobar-Morreale and Millan 2007). Barbosa-Desongles et al. (2013) have demonstrated that 
testosterone treatment significantly increases the proliferation of human visceral pre-adipocytes in culture. In a case-control study, Echiburu et al. (2018) found that in PCOS women the adipocyte area was positively correlated with serum testosterone and visceral adipose tissue volume. In the same study, the visceral adipose tissue of the PCOS group had on average $49 \%$ greater area than that of women from the control group.

Follicular development. In addition to androgens and insulin, other hormones also have abnormal secretion in PCOS. These changes include follicle-stimulating hormone (FSH) deficiency and $\mathrm{LH}$ hypersecretion, increasing the $\mathrm{LH} / \mathrm{FSH}$ ratio in about 55 to $75 \%$ of the women with PCOS (Azziz et al. 2016; De Leo et al. 2016). Healthy women show a decrease in the secretion of gonadotrophin-releasing hormone $(\mathrm{GnRH})$ in the luteal phase due to a negative feedback caused by progesterone. However, in PCOS women, hyperandrogenism reduces progesterone negative feedback on GnRH (Burt Solorzano et al. 2012; Rojas et al. 2014), therefore a fast $\mathrm{GnRH}$ pulse frequency is observed in this group, favoring the production of LH over FSH (Burt Solorzano et al. 2012; Azziz et al. 2016; Cimino et al. 2016; De Leo et al. 2016). In vitro studies have shown that hypothalamus and pituitary gland have insulin receptors, which can stimulate the release of FSH and $\mathrm{LH}$ directly in hyperinsulinemic status. However, it is still unclear whether the alterations of the hypothalamicpituitary axis in PCOS are primary or secondary to changes in steroid hormone secretion (De Leo et al. 2016). Hyperandrogenism is also related to an increase in abdominal adiposity (Dumesic et al. 2016), which contributes to the inflammatory character of PCOS and to the changes in lipid profile (Delitala et al. 2017).

Ovarian folliculogenesis is regulated by a delicate balance between extra and intra-ovarian factors. Disruption of this balance may muddle follicular development and formation of mature oocytes, leading to infertility (De Leo et al. 2016). In healthy women, oocytes mature under the influence of various hormones, mainly FSH, and LH stimulates ovulation as well as final oocyte maturation (Azziz et al. 2016). In women with PCOS, there may be early luteinization due to high levels of LH. These women tend to form several antral follicles whose development is interrupted prematurely (De Leo et al. 2016). The combination of these factors induces most follicles to stop at a small antral stage (Azziz et al. 2016), acquiring up to $2-5 \mathrm{~mm}$ in diameter, which is two to three times larger than that observed in normal ovaries (Kurobe et al. 2012).

In addition, women with PCOS have very high levels of AMH in serum and follicular fluid (Chang et al. 2013). This hormone is produced by granulosa cells and, in normal women, acts on the primordial follicle, inhibiting the recruitment of many follicles, and attenuates the effects of FSH on growing follicles. In women with PCOS, high levels of AMH lead to follicular resistance to $\mathrm{FSH}$, which also impairs the follicle growth (Kurobe et al. 2012), selection of a dominant follicle, and recruitment of more primordial follicles (Azziz et al. 2016). Furthermore, considering that FSH is also important to stimulate granulosa cells to convert androgens to estrogens (Chang et al. 2013), the antagonism of AMH to FSH contributes to hyperandrogenism in PCOS (Azziz et al. 2016).

Increased serum $\mathrm{AMH}$ is a common feature of PCOS and thus a potential biomarker of this syndrome (Dumont et al. 2015; Quinn et al. 2017). Serum $\mathrm{AMH}$ levels correlate with the number of ovarian follicles and cysts and therefore, AMH can be used as an alternative to transvaginal ultrasonography to detect polycystic ovarian morphology, which is one of the criteria for diagnosing PCOS (Karakas 2017). Its measurement is also useful in the management of infertility in women with PCOS and as a marker of treatment efficiency in relieving PCOS symptoms (Dumont et al. 2015).

Tata et al. (2018) have conducted an experimental study to evaluate the androgenic effects of increased levels of AMH on mouse pregnancy. The researches treated a group of pregnant female mice with phosphate buffered saline (PBS) and another group with recombinant $\mathrm{AMH}$ at the end of gestation. When comparing the groups, they observed an excess of maternal testosterone and decreased placental conversion of testosterone into estradiol in the AMH group. There was also a masculinization of the AMH exposed female fetuses, in addition to reproductive characteristics similar to those observed in human PCOS.

$\mathrm{GnRH}$-positive neurons express $\mathrm{AMH}$ receptors and exogenous AMH potently increases GnRH release (Cimino et al. 2016). Tata et al. (2018) have also treated pregnant mice with AMH and GnRH antagonist. As a result, prenatal GnRH antagonist treatment prevented the appearance of reproductive defects in the offspring.

Inflammation. There is an imbalance in PCOS between pro-inflammatory mediators and anti-inflammatory cytokines, which is associated with a systemic low-grade inflammation in these women (Duleba and 
Dokras 2012; Mortada et al. 2015; Soter et al. 2015; Aytan et al. 2016). Inflammation is considered to be a strong link between the numerous metabolic ramifications of the syndrome, such as IR, dyslipidemia, and T2DM (Repaci et al. 2011), and may also contribute to an increased risk of cardiovascular complications in PCOS (Repaci et al. 2011; Soter et al. 2015; Carvalho et al. 2017b).

Obesity, especially the visceral phenotype, causes an increase in the plasma levels of inflammatory mediators (Repaci et al. 2011; Aytan et al. 2016), which is particularly relevant considering that women with PCOS tend to accumulate more fat in the abdominal region (Sam 2007). Adipocytes are able to activate the complement system and produce inflammatory cytokines (Wellen and Horamisligil 2013). Adipocytes from obese individuals show an increased release of proinflammatory adipokines, including tumor necrosis factor $\alpha$ (TNF- $\alpha$ ) and interleukin-6 (IL-6) (Santos and Torrent 2010; Lehr et al. 2012). Adipokines act in an autocrine, paracrine and endocrine form, presenting local to systemic effects (Santos and Torrent 2010). The expression of proinflammatory adipokines is increased in PCOS and is proportional to adiposity and body mass index (Sarray et al. 2015).

The subcutaneous adipose tissue releases high amounts of anti-inflammatory factors such as adiponectin and does not produce significant amounts of TNF- $\alpha$, whereas the visceral adipose tissue releases pro-inflammatory mediators such as TNF- $\alpha$ and IL-6 (Santos and Torrent 2010), increasing the risk of cardiovascular diseases (Santos and Torrent 2010) and T2DM (Kopelman 2000).

PCOS women show increased levels of plasma TNF- $\alpha$ (Mahde et al. 2009; Thathapudi et al. 2014), which is mostly secreted by macrophages and visceral adipose tissue (Wang et al. 2005; Santos and Torrent 2010). TNF- $\alpha$ stimulates the phosphorylation of the Insulin Receptor Substrate 1 (IRS-1) protein, inhibiting the signaling pathway of this hormone, which contributes to IR (Wang et al. 2005; Santos and Torrent 2010). Moreover, TNF- $\alpha$ stimulates lipolysis in human adipocytes (Zhang et al. 2002; Green et al. 2004; Wang et al. 2005), which increases circulating free fatty acids and may contribute to the development of cardiovascular diseases (Green et al. 2004). TNF- $\alpha$ also contributes to the atherogenesis process by stimulating the migration of monocytes and their differentiation into macrophages within the endothelial wall (Fonseca-Alaniz et al. 2007). Some studies (Wilson et al. 1997; Vural et al. 2010) have suggested that TNF- $\alpha$ promoter gene polymorphisms may be associated with PCOS risk.
IL-6 is an important proinflammatory cytokine in chronic inflammation (Zheng and Li 2016). The adipose tissue produces about 15 to $30 \%$ of circulating IL-6 levels, and the visceral fat contributes most of this production. It is also produced by cells of the immune system, such as macrophages and mast cells, besides endothelial cells and fibroblasts (Santos and Torrent 2010). IL-6 levels are elevated in obese individuals (Eder et al. 2009) and in women with PCOS (Zheng and Li 2016). Women treated with metformin have a reduction in IL-6 levels, which is probably related to the improvement of insulin sensitivity induced by this drug (Xu et al. 2014). IL-6 activates immune system cells (Santos and Torrent 2010), stimulates lipolysis in adipocytes increasing levels of circulating free fatty acids (Van-Hall et al. 2003) and is related to cardiovascular complications (Zheng et al. 2016). A systematic review and meta-analysis included 25 case-control studies and a total of 1618 women $(922$ PCOS patients and 696 healthy women) and concluded that IL-6 levels were significantly lower in controls than in PCOS patients (Peng et al. 2016). This study has suggested that higher IL-6 levels are significantly associated with HOMA-IR and total testosterone in lean and obese women with PCOS. In conclusion, IL-6 levels may be a useful monitoring biomarker for the prognosis in PCOS women.

We have demonstrated that IL-6 -179C/G polymorphism was associated with higher glucose levels in PCOS women. The IL-10 -1082A/G, -819A/T and $-522 \mathrm{~A} / \mathrm{G}$ polymorphisms, as well as IFN- $\gamma+874 \mathrm{~T} / \mathrm{A}$ polymorphism, were associated with lower total cholesterol and triglyceride levels in this group. The IL-10 $-1082 \mathrm{~A} / \mathrm{G}$ and the TGF- $\beta 1$ 10T/C polymorphisms were associated with lower and higher clinical hyperandrogenism, respectively, in PCOS women. In addition, the TGF- $\beta 110 \mathrm{~T} / \mathrm{C}$ polymorphism was associated with a lower lipid accumulation product (LAP) index and higher high-density lipoprotein cholesterol (HDL-c) levels in the PCOS group (Soter et al. 2015).

PCOS is associated with low serum adiponectin levels (Vrbikova et al. 2005; Liu and Nair 2010; Mirza et al. 2014). Adiponectin is an abundant adipokine produced and secreted exclusively by the adipose tissue. Adiponectin has anti-inflammatory, antiatherogenic, cardioprotective, and insulin-sensitizing effects in the liver and muscle (Santos and Torrent 2010; Sarray et al. 2015). Regarding lipid metabolism, adiponectin reduces the production of triglycerides and serum levels of free fatty acids (Santos and Torrent 2010). A systematic review of 15 studies indicated that adiponectin is linked to IR, BMI and adiposity in women with PCOS (Groth 2010). 
Proteomic studies have suggested that haptoglobin - an inflammatory acute phase glycoprotein - may be also associated to PCOS (Matharoo-Ball et al. 2007; Insenser et al. 2010). More recently, we conducted a case-control study (Carvalho et al. 2017b) that showed higher plasma haptoglobin levels in the PCOS group than in controls. In the aforementioned study, haptoglobin also showed a positive correlation with C-reactive protein (CRP) and pro-oxidative profile in the PCOS group.

Another promising inflammatory marker for PCOS is the amount of circulating microparticles (MPs) derived from leukocytes (LMPs). Recently, we conducted a case-control study with 50 PCOS patients and 50 healthy controls, in which we have observed increased total MPs and LMPs in the PCOS group. Microparticles are extracellular vesicles with 0.1-1 $\mu \mathrm{m}$ released from the cell membrane during cell activation and apoptosis and carry signaling molecules. Therefore, MPs are important messengers in cell-cell communication. LMPs may originate from neutrophils, monocytes/ macrophages, and lymphocytes. High levels of LMPs in PCOS women reflect leukocyte activation and systemic low-grade inflammation (Carvalho et al. 2017a). LMPs can promote leukocyte-leukocyte interactions (Miller et al. 2016), modify the endothelial function (Mesri and Altieri 1998), take part in coagulation and platelet activation and promote the recruitment of inflammatory cells in the vascular wall, which are all necessary processes for the progression of the atherosclerotic lesion (Wojta 2015). Consequently, increased LMPs levels in PCOS women could be involved in the altered hemostasis and inflammation.

Dyslipidemia. Dyslipidemia is highly prevalent among patients with PCOS. According to the National Cholesterol Education Program (NCEP), approximately $70 \%$ of the women affected by the syndrome present changes in lipid profile (NCEP 2002) and these changes are mainly found after the fourth decade of life (Macut et al. 2013). Women with PCOS tend to present higher levels of triglycerides, low density lipoprotein-cholesterol (LDL-c), and very low-density lipoprotein-cholesterol (VLDLc) (Diamanti-Kandarakis et al. 2007), which are characterized by pro-atherogenic potential. In contrast, women with PCOS have low levels of HDL-c, which plays an antiatherogenic role (Spritzer et al. 2001; Bagatini 2010; Rocha et al. 2010; Macut et al. 2013). Such alterations in the lipid profile are typically observed in IR disorders and associated with increased risk of cardiovascular diseases (Rocha et al. 2010). The family history of dyslipidemia is also frequent in cases of PCOS (Diamanti-Kandarakis et al. 2007), which is related to the hereditary aspects of the syndrome.

Lipolysis is a catabolic process characterized by breakdown of triglycerides stored in adipocytes, releasing non-esterified fatty acids and glycerol (Langin 2006), which are proportional to visceral adiposity (Arner 2005). As women with PCOS tend to have greater adiposity in the abdominal cavity (EscobarMorreale and Millan 2007), the release of fatty acids by lipolysis is more evident in this group (Arner 2005). Considering that visceral fat communicates with the liver through the portal vein, visceral lipolysis has major effects on this organ, characterized mainly by hepatic steatosis (Arner 2005). Moreover, increasing the flow of free fatty acids to the liver stimulates the secretion and assembly of VLDL-c (Diamanti-Kandarakis et al. 2007; Nielsen and Karpe 2012).

Testosterone regulates positively two genes involved in HDL-c catabolism: the SR-BI receptor gene (Scavenger receptor class B type I) and the hepatic lipase gene (Diamanti-Kandarakis et al. 2007; Vodo et al. 2013). In the liver, SR-BI protein plays an important role in lipid homeostasis by selectively capturing cholesterol esters from HDL-c and increasing hepatic cholesterol excretion (Song et al. 2015). Hepatic lipase hydrolyzes phospholipids on the surface of HDL, facilitating the selective uptake of HDL-c lipids by SRB1 (Vodo et al. 2013). Thus, it is believed that the effect of testosterone on these two proteins (SR-B1 and hepatic lipase) leads to a decrease in HDL-c and an increase in total serum cholesterol in hyperandrogenic conditions, corroborating with these common findings in PCOS women (Diamanti-Kandarakis et al. 2007).

Proprotein convertase subtilisin kexin type 9 (PCSK9) is a new component of lipid metabolism that is correlated to the development of dyslipidemia and atherosclerosis. This protein acts by preventing the recycling of LDL receptors (LDL-r) back to the cell surface and thus generates higher levels of LDLc. Recently, we demonstrated that the GG genotype in PCSK9 rs562556 polymorphism was associated with higher HDL-c in PCOS women, while AA genotype carriers had higher plasma testosterone levels, suggesting the relationship between dyslipidemia and androgenic status in PCOS women (Xavier et al. 2018).

A higher level of oxidized LDL-c is also found in women with PCOS when compared to controls (Macut et al. 2006), which is directly related to the pathogenesis of atherosclerosis (Birukov 2006). 
Visceral obesity is strongly associated with IR, dyslipidemia, and cardiovascular diseases (Ouchi et al. 2011), complications to which women with PCOS are more susceptible (Palomba et al. 2015; Azziz et al. 2016; Pavaleanu et al. 2016; Papadakis et al. 2017). IR is indicated as a key element in the dyslipidemia of patients with PCOS. Women with PCOS and T2DM show a significantly higher prevalence of lipid abnormalities (88\%) compared to women with normal glucose tolerance (58\%) (Diamanti-Kandarakis et al. 2007). The use of drugs that increase insulin sensitivity tends to improve the lipid profile of patients (Macut et al. 2013), and also reduces their cardiovascular risk (Lamanna et al. 2011).

Oxidative stress. Artimani et al. (2018) have evaluated follicular fluid samples of 21 PCOS women compared to 21 women with normal ovarian function. The oxidative stress was examined by measuring total oxidant status (TOS), malondialdehyde (MDA), total antioxidant capacity (TAC), and thiol groups. They have observed that PCOS women had an elevated concentration of MDA and TOS compared to controls. Besides, levels of TAC and thiol groups were lower in PCOS compared to controls. In agreement, Di Segni et al. (2017) observed significantly higher MDA levels in peripheral mononuclear cells from PCOS than in controls. Ozer et al. (2016) have evaluated 71 women with PCOS and 53 healthy controls and found higher MDA and glutathione peroxidase and lower serum catalase levels than in the control group. Infertile PCOS patients had also significantly higher MDA and lower catalase levels than fertile PCOS patients.

Murri et al. (2013) have performed a meta-analysis covering 68 studies that evaluated oxidative stress in PCOS. These studies have included 4933 patients with PCOS and 3671 controls. Compared to the control group, patients with PCOS had higher circulating concentrations of homocysteine (23\% increase), malondialdehyde (47\% increase) and asymmetric dimethylarginine (ADMA) (36\% increase), increased activity of superoxide dismutase (34\% increase) and decreased levels of glutathione (50\% decrease) and paraoxonase-1 (32\% decrease). Similar results were found by restricting analyzes to studies in which patients and controls were matched for age and BMI. Based on these results, Murri et al. (2013) have concluded that circulating markers of oxidative stress are elevated in women with PCOS compared to healthy women, regardless of the weight, suggesting that oxidative stress may participate in the pathogenesis of PCOS.
Several publications have suggested that supplementation with different types of antioxidants has beneficial effects for these patients, with reduction in androgen levels (Razavi et al. 2016), improvement of oxidative markers (Foroozanfard et al. 2015; Razavi et al. 2016), decreased ovarian size, reduction of antral follicle number (Ghafurniyan et al. 2015), improvement in IR (Foroozanfard et al. 2015; Ghafurniyan et al. 2015), reduction of inflammatory parameters (Foroozanfard et al. 2015; Mombaini et al. 2017), and anthropometric indices (Mombaini et al. 2017).

Oxidative status probably contributes to inflammation in PCOS (Gonzalez et al. 2006), and may be related to its pathogenesis and have close interactions with characteristics such as IR, hyperandrogenism and cardiovascular risk (Zuo et al. 2016). Reactive oxygen species (ROS) could induce releasing of inflammatory factors and inflammatory response, by activating the associated signaling pathways of nuclear factor- $\kappa \mathrm{B}$ (NF- $\mathrm{kB}$ ), activated protein-1 (AP-1), and hypoxia-inducible factor-1 (HIF-1). Besides, inflammation could induce IR due to interference on post-insulin receptor signaling mechanisms, such as the insulin receptor substrate 1-phosphatidyl inositol 3 kinase-protein kinase B (IRS1-PI3K-PKB/Akt) pathway (Zuo et al. 2016). Moreover, oxidative stress could enhance the activity of ovarian steroidogenic enzymes, which could stimulate androgen generation, and TNF- $\alpha$ may promote the proliferation of theca-interstitial cells and the synthesis of androgens (Zuo et al. 2016).

Oxidative stress may also be related to a higher incidence of cancer in PCOS women (Shen et al. 2015) by inducing DNA damage, such as DNA chain rupture, base modification, DNA-DNA crosslinking, DNA-protein crosslinking, and also epigenetic changes, including elevated DNA methylation level (Zuo et al. 2016).

Hemostatic imbalance. Hemostasis is also worth highlighting in the study of PCOS, since women affected by this syndrome have an imbalance between pro-coagulant and anticoagulant mediators, with a moderate prothrombotic tendency (Targuer et al. 2014) and a consequently increased thromboembolic risk (Gonzalez et al. 2013; Azziz et al. 2016; Burchall et al. 2016; Papadakis et al. 2017). Targuer et al. (2014) have emphasized that there are few studies about the hemostatic profile of PCOS women, usually involving small samples. It is clear that PCOS is associated with increased platelet count, platelet aggregation, and a decrease in plasma fibrinolytic activity (Targuer et al. 2014), but the mechanisms of hemostatic disturbance 
in PCOS still need to be better clarified (MannerasHolm et al. 2011).

Endothelial dysfunction seems to play an important role in the pro-coagulating tendency of PCOS (Targuer et al. 2014). Although the von Willebrand factor presents similar levels among women with and without PCOS, their levels are significantly elevated in obese women with the syndrome (Koiou et al. 2012).

Some studies have shown increased levels of asymmetric dimethylarginine (ADMA) in PCOS women (Moran et al. 2009; Targuer et al. 2014). Increased ADMA levels are associated with a reduced production of nitric oxide and, consequently, an increase in systemic vascular resistance and in the risk of developing cardiovascular diseases (Deligeoroglou et al. 2012).

Plasminogen activator inhibitor-1 (PAI-1) is an important marker of thromboembolic risk because it inhibits tissue plasminogen activator (tPA) and urokinase (uPA), which act to convert plasminogen to plasmin, a fibrinolytic enzyme. Thus, high levels of PAI-1 indicate a loss of fibrinolytic activity and therefore, a higher risk of thrombosis. In a casecontrol study that included 79 patients with PCOS and 79 healthy controls, we have demonstrated that PAI-1 levels are positively correlated with proinflammatory factors in the PCOS group. PAI-1 has a positive correlation with glycemia, BMI, abdominal circumference, HOMA-IR, VLDL-c, LAP, triglycerides, vitamin $\mathrm{D}$ and soluble vascular cell adhesion molecule-1 (sVCAM-1) levels (Sales et al. 2013). Accordingly, obese women with PCOS presented increased levels of PAI-1. Moreover, the $4 \mathrm{G}$ allele in PAI-1 gene was more frequent in the PCOS group, and the 4G/4G genotype was associated with the highest PAI-1 levels in this population (Sales et al. 2013).
Tissue factor (TF) is also increased in women with PCOS (Gonzalez et al. 2013). It is a transmembrane receptor for factor VII/VIIa and this binding leads to the activation of the extrinsic coagulation pathway (Mackman 2009). We compared total MPs and MPsexpressing TF (TFMPs) in the plasma of patients with PCOS that used metformin ( $850 \mathrm{mg} 2 \times /$ day during at least 6 months) and another PCOS group without treatment. Total MPs levels were lower in treated patients when compared to the untreated group. Plasma levels of TFMPs were also significantly lower in the group of patients who used metformin when compared to untreated patients, suggesting that metformin could have an antithrombotic effect in PCOS women (Carvalho et al. 2017c).

\section{Conclusion}

PCOS is the commonest hormonal disorder affecting the reproductive age women. As a syndrome, the pathophysiology has complex molecular pathways, with multiple components, such as hormonal, inflammatory, metabolic, and hemostatic alterations, characterized mainly by IR and hyperandrogenism. Studies with focus on the genetic and environmental PCOS determinants are still needed to support the development of new and consistent treatment methods, besides identifying effective strategies for the prevention of this relevant endocrine syndrome.

\section{Acknowledgements}

Conselho Nacional de Desenvolvimento Cientifico e Tecnologico (CNPq), Coordenacao de Aperfeicoamento de Pessoal do Ensino Superior (CAPES) and Fundacao de Amparo a Pesquisa de Minas Gerais (FAPEMIG) for the financial support. FMR and KBG are grateful to $\mathrm{CNPq}$ Research Fellowship.

\section{References}

Al-Eisa E, Gabr SA, Alghadir AH. Effects of supervised aerobic training on the levels of anti-Mullerian hormone and adiposity measures in women with normo-ovulatory and polycystic ovary syndrome. J Pak Med Assoc 67, 499-507, 2017.

Arner P. Human fat cell lipolysis: biochemistry, regulation and clinical role. Best Pract Res Clin Endocrinol Metab 19, 471-482, 2005.

Artimani T, Karimi J, Mehdizadeh M, Yavangi M, Khanlarzadeh E, Ghorbani M, Asadi S, Kheiripour N. Evaluation of pro-oxidant-antioxidant balance $(\mathrm{PAB})$ and its association with inflammatory cytokines in polycystic ovary syndrome (PCOS). Gynecol Endocrinol 34, 148-152, 2018.

Aytan AN, Bastu E, Demiral I., Blulut H, Dogan M, Buyru F. Relationship between hyperandrogenism, obesity, inflammation and polycystic ovary syndrome. Gynecol Endocrinol 32, 709-713, 2016.

Azziz R, Marin C, Hoq L, Badamgarav E, Song P. Health care-related economic burden of the polycystic ovary syndrome during the reproductive life span. J Clin Endocrinol 90, 4650-4658, 2005. 
Azziz R. Polycystic Ovary Syndrome Is a Family Affair. J Clin Endocrinol Metab 93, 1579-1581, 2008.

Azziz R, Carmina E, Chen Z, Dunaif A, Laven JS, Legro RS, Lizneva D, Natterson-Horowtiz B, Teede HJ, Yildiz BO. Polycystic ovary syndrome. Nat Rev Dis Primers 2, 16057, 2016.

Bachanek M, Abdalla N, Cendrowski K, Sawicki W. Value of ultrasonography in the diagnosis of polycystic ovary syndrome - literature review. J Ultrason 15, 410-422, 2015.

Bachelot A. Polycystic ovarian syndrome: clinical and biological diagnosis. Ann Biol Clin Ann Biol Clin (Paris) 74, 661-667, 2016.

Bagatini SR. Polimorfismos do gene da adiponectina e variaveis clinicas, metabolicas e hormonais em mulheres com ousem a sindrome dos ovarios policisticos (PCOS) e a investigacao de um modelo animal para o estudo da PCOS. Doctoral thesis - Physiology Program - Universidade Federal do Rio Grande do Sul. Porto Alegre, Rio Grande do Sul, 2010.

Barbosa-Desongles A, Hernandez C, Simo R, Selva DM. Testosterone induces cell proliferation and cell cycle gene overexpression in human visceral preadipocytes. Am J Physiol Cell Physiol 305, C355-C359, 2013.

Bartha JL, Comino-Delgado R, Romero-Carmona R, Gomez-Jaen MC. Sex hormone-binding globulin in gestational diabetes. Acta Obstet Gynecol Scand 79, 839-845, 2000.

Birukov KG. Oxidized lipids: the two faces of vascular inflammation. Curr Atheroscler Rep 8, 223-231, 2006.

Burchall GF, Piva TJ, Linden MD, Gibson-Helm ME, Ranasinha S, Teede HJ. Comprehensive assessment of the hemostatic system in polycystic ovarian syndrome. Semin Thromb Hemost 42, 55-62, 2016.

Burt Solorzano CM, Beller JP, Abshire MY, Collins JS, McCartney CR, Marshall JC. Neuroendocrine dysfunction in polycystic ovary syndrome. Steroids 77, 332-337, 2012.

Burtis CA, Ashwood EA, Tietz BD. Fundamentos de Quimica Clinica, 6ed. Filadelfia: Saunders, pp. 984, 2008.

Carvalho LML, Ferreira CN, Soter MO, Sales MF, Rodrigues KF, Martins SR, Candido AL, Reis FM, Silva IFO, Campos FMF, Gomes KB. Microparticles: Inflammatory and haemostatic biomarkers in Polycystic Ovary Syndrome. Mol Cell Endocrinol 443, 155-162, 2017a.

Carvalho LML, Ferreira CN, De Oliveira DKD, Rodrigues KD, Duarte RCF, Teixeira MFA, Xavier LB, Candido AL, Reis FM, Silva IFO, Campos FMF, Gomes KB. Haptoglobin levels, but not Hp1-Hp2 polymorphism, are associated with polycystic ovary syndrome. J Assist Reprod Genet 34, 1691-1698, 2017b.

Carvalho LML, Ferreira CN, Candido AL, Reis FM, Soter MO, Sales MD, Silva IFO, Nunes FC, Gomes KB. Metformin reduces total microparticles and microparticles-expressing tissue factor in women with polycystic ovary syndrome. Arch Gynecol Obstet 296, 617-621, 2017c.

Chang HM, Klausen C, Leung PCK. Antimüllerian hormone inhibits follicle-stimulating hormone-induced adenylyl cyclase activation, aromatase expression, and estradiol production in human granulosa-lutein cells. Fertil Steril 100, 585-592, 2013.

Chen J, Shen S, Tan Y, Xia D, Cia Y, Cao Y, Cao Y, Wang W, Wu X, Wang H, Yi L, Gao Q, Wang Y. The correlation of aromatase activity and obesity in women with or without polycystic ovary syndrome. J Ovarian Res 22, $11,2015$.

Cimino I, Casoni F, Liu X. Novel role for anti-Müllerian hormone in the regulation of GnRH neuron excitability and hormone secretion. Nat Commun 7, 10055, 2016.

De Leo V, Musacchio MC, Cappelli V, Massaro MG, Morgante G, Petraglia F. Genetic, hormonal and metabolic aspects of PCOS: an update. Reprod Biol Endocrinol 14, 38, 2016.

Deligeoroglou E, Vrachnis N, Athanasopoulos N, Iliodromiti Z, Sifakis S, Iliodromiti S, Siristatidis C, Creatsas G. Mediators of chronic inflammation in polycystic ovarian syndrome. Gynecol Endocrinol, 28, 974-978, 2012.

Delitala AP, Capobianco G, Delitala G, Cherchi PL, Dessole S. Polycystic ovary syndrome, adipose tissue and metabolic syndrome. Arch Gynecol Obstet 296, 405-419, 2017.

Deswal R, Yadav A, Dang AS. Sex hormone binding globulin - an important biomarker for predicting PCOS risk: A systematic review and meta-analysis. Syst Biol Reprod Med 64, 12-24, 2018.

Diamanti-Kandarakis E, Papavassiliou AG, Kandrarakis SA, Chrousos GP. Focus on Polycystic Ovary Syndrome pathophysiology and types of dyslipidemia in PCOS. Trends Endocrinol Metab 19, 280-285, 2007.

Di Segni C, Silvestrini A, Fato R, Bergamini C, Guidi F, Raimondo S, Meucci E, Romualdi D, Apa R, Lanzone A, Mancini A. Plasmatic and intracellular markers of oxidative stress in normal weight and obese patients with Polycystic Ovary Syndrome. Exp Clin Endocrinol Diabetes 125, 506-513, 2017.

Duleba AJ, Dokras A. Is PCOS an inflammatory process? Fertil Steril 97, 7-12, 2012.

Dumesic DA, Akopians AL, Madrigal VK. Hyperandrogenism accompanies increased intra-abdominal fat storage in normal weight Polycystic Ovary Syndrome women. J Clin Endocrinol Metab 101, 4178-4188, 2016. 
Dumont A, Robin G, Catteau-Jonard S, Dewailly D. Role of anti-Müllerian hormone in pathophysiology, diagnosis and treatment of Polycystic Ovary Syndrome: a review. Reprod Biol Endocrinol 13, 137, 2015.

Dunaif A. Perspectives in Polycystic Ovary Syndrome: From hair to eternity. J Clin Endocrinol Metab 101, 759-768, 2016.

Echiburu B, Perez-Bravo F, Galgani JE, Sandoval D, Saldias C, Crisosto N, Maliqueo M, Sir-Petermann T. Enlarged adipocytes in subcutaneous adipose tissue associated to hyperandrogenism and visceral adipose tissue volume in women with polycystic ovary syndrome. Steroids 130, 15-21, 2018.

Eder K, Baffy N, Falus A, Fulop AK. The major inflammatory mediator interleukin-6 and obesity. Inflamm Res 58, 727-736, 2009.

Escobar-Morreale HF, San Millan JL. Abdominal adiposity and the polycystic ovary syndrome. Trends Endocrinol Metab 18, 266-272, 2007.

Faghfoori Z, Fazelian S, Shadnoush M, Goodarzi R. Nutritional management in women with polycystic ovary syndrome: A review study. Diabetes Metab Syndr 11, 429-432, 2017.

Fan W, Li S, Chen Q, Huang Z. Association between the (TAAAA)n SHBG polymorphism and PCOS: a systematic review and meta-analysis. Gynecol Endocrinol 29, 645-650, 2013.

Fonseca-Alaniz MH, Takada J, Alonso-Vale MI, Lima FB. Adipose tissue as an endocrine organ: from theory to practice. J Pediatr 83, 192-203, 2007.

Foroozanfard F, Jamilian M, Bahmani F, Talaee R, Talaee N, Hashmi T, Nasri K, Asemi Z, Esmaillzadeh A. Calcium plus vitamin D supplementation influences biomarkers of inflammation and oxidative stress in overweight and vitamin D-deficient women with polycystic ovary syndrome: a randomized double-blind placebo-controlled clinical trial. Clin Endocrinol 83, 888-894, 2015.

Ghafurniyan H, Azarnia M, Nabiuni M, Karimzadeh L. The effect of green tea extract on reproductive improvement in estradiol valerate-induced polycystic ovary Polycystic Ovarian Syndrome in rat. Iran J Pharm Res 14, 1215-1233, 2015.

Glintborg D, Andersen M. Management of endocrine disease: morbidity in polycystic ovary syndrome. Eur J Endocrinol 176, R53-R65, 2017.

Gonzalez F, Rote NS, Minium J, Kirwan JP. Reactive oxygen species-induced oxidative stress in the development of insulin resistance and hyperandrogenism in polycystic ovary syndrome. J Clin Endocrinol Metab 91, 336-340, 2006.

Gonzalez F, Kirwan JP, Rote NS, Minium J. Elevated circulating levels of tissue factor in polycystic ovary syndrome. Clin Appl Thromb Hemost 19, 66-72, 2013.

Goodarzi MO, Shah NA, Antoine HJ, Pall M, Guo X, Azziz R. Variants in the 5alpha-reductase type 1 and type 2 genes are associated with polycystic ovary syndrome and the severity of hirsutism in affected women. J Clin Endocrinol Metab 91, 4085-4091, 2006.

Green A, Rumberger JM, Stuart CA, Ruhoff MS. Stimulation of lipolysis by tumor necrosis factor-alpha in 3T3-L1 adipocytes is glucose dependent: implications for long-term regulation of lipolysis. Diabetes 53, 74-81, 2004.

Groth SW. Adiponectin and polycystic ovary syndrome. Biol Res Nurs 12, 62-72, 2010.

Hosseini AH, Kohan L, Aledavood A, Rostami S. Association of miR-146a rs2910164 and miR-222 rs2858060 polymorphisms with the risk of polycystic ovary syndrome in Iranian women: A case-control study. Taiwan J Obstet Gynecol 56, 652-656, 2017.

Insenser M, Martinez-Garcia MA, San-Milan JL, Escobar-Morreale HF. Proteomic analysis of plasma in the Polycystic Ovary Syndrome identifies novel markers involved in iron metabolism, Acute-Phase Response, and Inflammation. J Clin Endocrinol Metab 95, 3863-3870, 2010.

Insenser M, Escobar-Morreale. Proteomics and polycystic ovary syndrome. Expert Rev Proteomics 10, 435-447, 2013.

Jayasena C, Franks S. The management of patients with polycystic ovary syndrome. Nature Reviews Endocrinology 10, 624-636, 2014.

Jakimiuk AJ, Weitsman SR, Magoffin DA. 5alpha-reductase activity in women with polycystic ovary syndrome. J Clin Endocrinol Metab 84, 2414-2418, 1999.

Jalilian A, Kiani F, Sayehmiri F, Sayehmiri K, Khodaee Z, Akbari M. Prevalence of polycystic ovary syndrome and its associated complications in Iranian women: A meta-analysis. Iran J Reprod Med 13, 591-604, 2015.

Jia H, Yu L, Guo X, Gao W, Jiang Z. Associations of adiponectin gene polymorphisms with polycystic ovary syndrome: a meta-analysis. Endocrine 42, 299-306, 2012.

Jiao J, Fang Y, Wang T, Wang Z, Zhuou M, Wang X. Epidemiologic investigation of polycystic ovarian syndrome (PCOS) in Han ethnic women of reproductive age in Liaoning Province, China. Clin Exp Obstet Gynecol 41, 304-309, 2014. 
Joham AE, Teede HJ, Ranasinha S, Zoungas S, Boyele J. Prevalence of infertility and use of fertility treatment in women with polycystic ovary syndrome: data from a large community-based cohort study. J Womens Health (Larchmt) 24, 299-307, 2015.

Kahsar-Miller M, Azziz R. The development of the polycystic ovary syndrome: family history as a risk factor. Trends Endocrinol Metab 9, 55-58, 1998.

Karakas SE. New biomarkers for diagnosis and management of polycystic ovary syndrome. Clin Chim Acta. 471, 248-253, 2017.

Koiou E, Tziomalos K, Katsikis I, Dinas K, Tsourdi EA, Delkos D, Papadakis E, Panidis D. Plasma Von Willebrand factor antigen levels are elevated in the classic phenotypes of polycystic ovary syndrome. Hormones 11 , 77-85, 2012.

Kopelman PG. Obesity as a medical problem. Nature 404, 635-643, 2000.

Kristiansen SB, Endoh A, Casson PR, Buster JE, Hornsby PJ. Induction of steroidogenic enzyme genes by insulin and IGF-I in cultured adult human adrenocortical cells. Steroids 62, 258-265, 1997.

Kurobe FMC, Dzik A, Cavagna M, Drezett J. Importancia do hormonio anti-Mullerian on a infertilidade. Reprod Clim 27 104-108, 2012.

Lamanna C, Monami M, Marchionni N, Mannucci EE. Effect of metformin on cardiovascular events and mortality: a meta-analysis of randomized clinical trials. Diabetes Obes Metab 13, 221-228, 2011.

Langin D. Control of fatty acid and glycerol release in adipose tissue lipolysis. C R Biol 329, 598-607, 2006.

Lehr S, Hartwig S, Sell H. Adipokines: A treasure trove for the discovery of biomarkers for metabolic disorders. Proteomics Clin Appl 6, 91-101, 2012.

Liu Y, Nair MG. An efficient and economical MTT assay for determining the antioxidant activity of plant natural product extracts and pure compounds. J Nat Prod 73, 1193-1195, 2010.

Liu H, Zhao H, Chen ZJ. Genome-wide association studies for Polycystic Ovary Syndrome. Semin Reprod Med 34, $224-229,2016$

Mackman N. The role of tissue factor and factor VIIa in hemostasis. Anesth Analg 108, 1447-1452, 2009.

Macut D, Damjanovic S, Panidis D, Spanos N, Glisic B, Petakov M, Rousso D, Kourtis A, Bjekic J, Milic N. Oxidised low-density lipoprotein concentration - early marker of an altered lipid metabolism in young women with PCOS. Eur J Endocrinol 155, 131-136, 2006.

MacutD, Bjekic-Macut J, Savic-Radojevic A. Dyslipidemia and oxidativestress in PCOS. Front Horm Res 40, 51-63, 2013. Magoffin DA. Ovarian theca cell. Int J Biochem Cell Biol 37, 1344-1349, 2005.

Mahde A, Shaker M, Al-Mashhadani Z. Study of Omentin1 and Other Adipokines and Hormones in PCOS Patients. Oman Med J 24, 108-18, 2009.

Maliqueo M, Sun M, Johansson J, Benrick A, Labrie F, Svensson H, Lonn M, Duleba AJ, Stener-Victorin E. Continuous administration of a P450 aromatase inhibitor induces Polycystic Ovary Syndrome with a metabolic and endocrine phenotype in female rats at adult age. Endocrinology 154, 434-445, 2013.

Manneras-Holm L, Baghaei F, Holm G, Janson PO, Ohlsson C, Lonn M, Stener-Victorin E. Coagulation and fibrinolytic disturbances in women with polycystic ovary syndrome. J Clin Endocrinol Metab 96, 1068-1076, 2011.

Matharoo-Ball B, Hughes C, Lancashire L, Tooth D, Ball G, Creaser C, Elgasim M, Rees R, Layfield R, Atiomo W. Characterization of biomarkers in polycystic ovary syndrome (PCOS) using multiple distinct proteomic platforms. J Proteome Res 6, 3321-3328, 2007.

Mesri M, Altieri DC. Endothelial cell activation by leukocyte microparticles. J Immunol 161, 4382-4387, 1998.

Miller VM, Lahr BD, Bailey KR, Hodis HN, Mulvagh SL, Jayachandran M. Specific cell-derived microvesicles: Linking endothelial function to carotid artery intima-media thickness in low cardiovascular risk menopausal women. Atherosclerosis 246, 24-28, 2016.

Mirza SS, Shafique K, Shaikh AR, Khan NA, Anwar Qureshi M. Association between circulating adiponectin levels and polycystic ovarian syndrome. J Ovarian Res 7, 18, 2014

Mombaini E, Jafarirad S, Husain D, Haghighizadeh MH, Padfar P. The impact of green tea supplementation on anthropometric indices and inflammatory cytokines in women with Polycystic Ovary Syndrome. Phytother Res 31, 747-754, 2017.

Moran LJ, Hutchison SK, Meyer C, Zoungas S, Teede HJ. A comprehensive assessment of endothelial function in overweight women with and without polycystic ovary syndrome. Clin Sci 116, 761-770, 2009.

Morgante G, Cappelli V, Di Sabatino A, Massaro MG, De Leo V. Polycystic ovary syndrome (PCOS) and hyperandrogenism: the role of a new natural association. Minerva Ginecol 67, 457-463, 2015.

Mortada R, Kallail KJ, Dong F, Karakas S. HbA1c in Patients with Polycystic Ovary Syndrome: A Potential Marker of Inflammation. J Reprod Infertil 16, 203-206, 2015. 
Murri M, Luque-Ramirez M, Insenser M, Ojeda-Ojeda M, Escobar-Morreale HF. Circulating markers of oxidative stress and polycystic ovary syndrome (PCOS): a systematic review and meta-analysis. Hum Reprod Update $19,268-288,2013$

Musmar S, Afaneh A, Mo'alla H. Epidemiology of polycystic ovary syndrome: a cross sectional study of university students at An-Najah national university-Palestine. Reprod Biol Endocrinol 11, 47, 2013.

Nahum R, Thong KJ, Hillier SG. Metabolic regulation of androgen production by human thecal cells in vitro. Hum Reprod 10, 75-81, 1995.

National Cholesterol Education Program (NCEP) Expert Panel on Detection, Evaluation, and Treatment of High Blood Cholesterol in Adults (Adult Treatment Panel III) Third Report of the National Cholesterol Education Program (NCEP) Expert Panel on Detection, Evaluation, and Treatment of High Blood Cholesterol in Adults (Adult Treatment Panel III) final report. Circulation 106, 3143-3421, 2002.

Nestler JE, Powers LP, Matt DW, Steingold KA, Plymate SR, Rittmaster RS, Clore JN, Blackard WG. A direct effect of hyperinsulinemia on serum sex hormone-binding globulin levels in obese women with the polycystic ovary syndrome. J Clin Endocrinol Metab 72, 83-89, 1991.

Nielsen S, Karpe F. Determinants of VLDL-triglycerides production. Curr Opin Lipidol 29, 321-326, 2012.

Norman RJ, Dewailly D, Legro RS, Hickey TE. Polycystic ovary syndrome. Lancet 370, 385-397, 2007.

Ouchi N, Parker JL, Lugus JJ, Walsh K. Adipokines in inflammation and metabolic disease. Nat Rev Immunol 11, 85-97, 2011.

Ozer A, Bakacak M, Kıran H, Ercan O, Kostu B, Kanat-Pektaș M, Kilinc M, Aslan F. Increased oxidative stress is associated with insulin resistance and infertility in polycystic ovary syndrome. Ginekol Pol 87, 733-738, 2016.

Palomba S, Falbo SSA, La Sala GB. Complications and challenges associated with polycystic ovary syndrome: current perspectives. Int J Womens Health 7, 745-763, 2015.

Papadakis G, Kandaraki E, Papalou O, Vryonidou A, Diamanti-Kandarakis E. Is cardiovascular risk in women with PCOS a real risk? Current insights. Minerva Endocrinol 42, 340-355, 2017.

Pavaleanu I, Gafitanu D, Popovici D, Duceac LD, Pavaleanu M. Treatment of metabolic alterations in Polycystic Ovary Syndrome. Rev Med Chir Soc Med Nat Iasi 120, 258-263, 2016.

Peng Z, Sun Y, Lv X, Zhang H, Liu C, Dai S. Interleukin-6 levels in women with Polycystic Ovary Syndrome: A systematic review and meta-analysis. PLoS One 11, e0148531, 2016.

Quinn MM, Kao CN, Ahmad AK, Haisenleder DJ, Santoro N, Eisenberg E, Legro RS, Cedars MI, Huddleston HG. Age-stratified thresholds of anti-Müllerian hormone improve prediction of polycystic ovary syndrome over a population-based threshold. Clin Endocrinol 87, 733-740, 2017.

Razavi M, Jamilian M, Karamali M, Bahmani F, Aghadovod E, Asemi Z. The effects of vitamin D-K-calcium co-supplementation on endocrine, inflammation, and oxidative stress biomarkers in vitamin D-deficient women with polycystic ovary syndrome: a randomized, double-blind, placebo-controlled trial. Horm Metab Res 48, 446-451, 2016.

Reddy TV, Govatati S, Deenadayal M, Shivaji S, Bhanoori M. Polymorphisms in the TFAM and PGC1- $\alpha$ genes and their association with polycystic ovary syndrome among South Indian women. Gene 641, 129-136, 2018.

Reis GVOP, Gontijo NA, Rodrigues KF, Alves MT, Ferreira CN, Gomes KB. Vitamin D receptor polymorphisms and the polycystic ovary syndrome: A systematic review. J Obstet Gynaecol Res 43, 436-446, 2017.

Repaci A, Gambineri A, Pasquali R. The role of low-grade inflammation in the polycystic ovary syndrome. Mol Cell Endocrinol 335, 30-41, 2011.

Rittmaster RS, Deshwal N, Lehman L. The role of adrenal hyperandrogenism, insulin resistance, and obesity in the pathogenesis of polycystic ovarian syndrome. J Clin Endocrinol Metab 76, 1295-1300, 1993.

Rocha MP, Maranhao RC, Maranhao RC, Seydell TM, Barcellos CRG, Baracat EC, Hayashida SAY, Bydlowski SP, Marcondes JAM. Metabolism of triglyceride-rich lipoproteins and lipid transfer to high-density lipoprotein in young obese and normal-weight patients with polycystic ovary syndrome. Fertil Steril 93, 1948-1956, 2010.

Rojas J, Chavez M, Olivar L, Rojas M, Morillo J, Mejias J, Calvo M, Bermudez V. Polycystic ovary syndrome, insulin resistance, and obesity: navigating the pathophysiologic labyrinth. Int J Reprod Med 2014, 719050, 2014.

Rosenfield RL, Ehrmann DA. The pathogenesis of Polycystic Ovary Syndrome (PCOS): The hypothesis of PCOS as functional ovarian hyperandrogenism revisited. Endocr Rev 37, 467-520, 2016.

Ruan Y, Ma J, Xie X. Association of IRS-1 and IRS-2 genes polymorphisms with polycysticovary syndrome: a metaanalysis. Endocr J 59, 601-619, 2012.

Sales MF, Soter MO, Candido AL, Fernandes AP, Oliveira FR, Ferreira ACS, Souza MO, Ferreira CN, Gomes KB. Correlation between plasminogen activator inhibitor-1 (PAI-1) promoter 4G/5G polymorphism and metabolic/proinflammatory factors in polycystic ovary syndrome. Gynecol Endocrinol 29, 936-939, 2013. 
Sam S. Obesity and Polycystic Ovary Syndrome. Obes Manag 3, 69-73, 2007.

Santos LC, Torrent IF. O tecido adiposo e a producao de adipocinas. Synthesis Revista Digital FAPAM 2, 110-119, 2010.

Sarray S, Madan S, Saleh LR, Mahmoud N, Almawi WY. Validity of adiponectin-to-leptin and adiponectin-to-resistin ratios as predictors of polycystic ovary syndrome. Fertil Steril 104, 460-466, 2015

Seyfart T, Friedrich N, Kische H, Bulow R, Wallaschofski H, Volzke H, Nauck M, Keevil BG, Haring R. Association of sex hormones with physical, laboratory, and imaging markers of anthropometry in men and women from the general population. PLoS One 13, e0189042, 2018.

Shen CC, Yang AC, Hung J, Hu LY, Tsai SJ. A nationwide population-based retrospective cohort study of the risk of uterine, ovarian and breast cancer in women with polycystic ovary syndrome. Oncologist 20, 45-49, 2015.

Silva FS, Soter MO, Sales MF, Candido AL, Reis FM, Silva IFO, Souza MO, Ferreira CN, Gomes KB. Estrogen receptor a lpha gene (ESR1) Pvu II and Xba I polymorphisms are associated to metabolic and proinflammatory factors in polycystic ovary syndrome. Gene 560, 44-49, 2015.

Skalba P, Dabkowska-Huc A, Kazimierczak W, Samojedny A, Samojedny MP, Chelmicki Z. Content of 5-alphareductase (type 1 and type 2) mRNA in dermal papillae from the lower abdominal region in women with hirsutism. Clin Exp Dermatol 31, 564-570, 2006.

Song GJ, Kim SM, Park KH, Kim J, Choi I, Cho KH. SR-BI mediates high density lipoprotein (HDL)-induced antiinflammatory effect in macrophages. Biochem Biophys Res Commun 457, 112-118, 2015.

Soter MO, Ferreira CN, Sales MF, Candido AL, Reis FM, Milagres KS, Ronda C, Silva IO, Sousa MO, Gomes KB. Peripheral blood-derived cytokine gene polymorphisms and metabolic profile in women with polycystic ovary syndrome. Cytokine 76, 227-235, 2015.

Spritzer PM, Poy M, Wiltgen D, Mylius LS, Capp E. Leptin concentrations in hirsute women with polycystic ovary syndrome or idiopathic hirsutism: influence on LH and relationship with hormonal, metabolic, and anthropometric measurements. Hum Reprod 16, 1340-1346, 2001.

Targuer G, Zoppini G, Bonora E, Moghetti P. Hemostatic and fibrinolytic abnormalities in polycystic ovary syndrome. Semin Thromb Hemost 40, 600-618, 2014.

Tata B, Mimouni NEH, Barbotin AL, Malone SA, Loyens A, Pigny P, Dewailly D, Catteau-Jonard S, SundströmPoromaa I, Piltonen TT, Dal Bello F, Medana C, Prevot V, Clasadonte J, Giacobini P. Elevated prenatal antiMüllerian hormone reprograms the fetus and induces polycystic ovary syndrome in adulthood. Nat Med 24, 834-846, 2018.

Tehrani FR, Simbar M, Tohidi M, Hosseinpanah F, Azizi F. The prevalence of polycystic ovary syndrome in a community sample of Iranian population: Iranian PCOS prevalence study. Reprod Biol Endocrinol 9, 39, 2011.

Thathapudi S, Kodati V, Raj AY, Addepallyn U, Katragadda A, Hasan Q. Role of TNF $\alpha$ in the etiopathogenesis of PCOS: a clinical, biochemical and molecular genetic study. Mol Cytogenet 7, 94, 2014.

Unluturk U, Sezgin E, Yildiz BO. Evolutionary determinants of polycystic ovary syndrome-part 1. Fertil Steril 106, $33-41,2016$.

Van-Hall G, Stennsberg A, Sacchetti M, Fischer C, Keeller C, Schjerling P, Hiscock N, Moller K, Saltin B, Febbraio MA, Pedersen BK. Interleukin-6 stimulates lipolysis and fat oxidation in humans. J Clin Endocrinol Metab 88, 3005-3010, 2003.

Vassiliadi DA, Barber TM, Hughes BA, McCarthy MI, Wass JA, Franks S, Nightingale P, Tomlinson JW, Arlt W, Stewart PM. Increased 5 alpha-reductase activity and adrenocortical drive in women with polycystic ovary syndrome. J Clin Endocrinol Metab 94, 3558-3566, 2009.

Vink JM, Ssadzadeh S, Lambalk CB, Boomsma DI. Heritability of Polycystic Ovary Syndrome in a Dutch TwinFamily Study. J Clin Endocrinol Metab 91, 2100-2104, 2006.

Vodo S, Bechi N, Petroni A, Muscoli C, Aloisi AM. Testosterone-induced effects on lipids and inflammation. Mediators Inflamm 2013, 1-8, 2013.

Vrbikova J, Dvorakova K, Hill M, Vcelak J, Stanicka S, Vankova M, Sramkova D, Vondra K, Bendlova B, Starka L. Determinants of circulating adiponectin in women with polycystic ovary syndrome. Gynecol Obstet Invest 60, 155-161, 2005.

Vural P, Degirmencioglu S, Saral NY, Akgul C. Tumor necrosis factor alpha (-308), interleukin-6 (-174) and interleukin-10 (-1082) gene polymorphisms in polycystic ovary syndrome. Eur J Obstet Gynecol Reprod Biol 150, $61-65,2010$

Wang Y, Ng MC, So WY, Ma R, Ko GT, Tong PC, Chan JC. Association between tumour necrosis factor-alpha G308A polymorphism and risk of nephropathy in obese Chinese type 2 diabetic patients. Nephrol Dial Transplant 20, 2733-2738, 2005. 
Wellen KE, Hotamisligil GS. Obesity-induced inflammatory changes in adipose tissue. J Clin Invest 112, 1785-1788, 2013.

Wilson AG, Symons JA, McDowell TL, McDevitt HO, Duff GW. Effects of a polymorphism in the human tumor necrosis factor a promoter on transcriptional activation. Proc Natl Acad Sci USA 94, 3195-3199, 1997.

Wojta J. Platelet-derived microparticles in patients with high cardiovascular risk and subclinical atherosclerosis. Thromb Haemost 114, 1099, 2015.

Xavier LB, Soter MO, Sales MF, Oliveira DKD, Reis HJ, Candido AL, Reis FM, Silva IO, Gomes KB, Ferreira CN. Evaluation of PCSK9 levels and its genetic polymorphisms in women with polycystic ovary syndrome. Gene 644, 129-136, 2018.

Xu X, Du C, Zheng Q, Peng L, Sun Y. Effect of metformin on serum interleukin-6 levels in polycystic ovary syndrome: a systematic review. BMC Womens Health 14, 93, 2014.

Zhang HH, Halbleib M, Ahmad F, Manganiello VC, Greenberg AS. Tumor necrosis factor-alpha stimulates lipolysis in differentiated human adipocytes through activation of extracellular signal-related kinase and elevation of intracellular cAMP. Diabetes 51, 2929-2935, 2002.

Zhao JL, Chen ZJ, Zhao LX, Geng L, Wang S, Gao SS, Zhang P, Liu S, Zhou FR. [Epidemiological study of clinical characteristics of Chinese Han ethnic women with polycystic ovary syndrome]. Zhonghua Fu Chan Ke Za Zhi 41, 375-379, 2006. [Article in Chinese].

Zhao H, Lv Y, Li L, Chen ZJ. Genetic studies on Polycystic Ovary Syndrome. Best Pract Res Clin Obstet Gynaecol 37, 56-65, 2016.

Zheng SH, Li XL. Visceral adiposity index as a predictor of clinical severity and therapeutic outcome of PCOS. Gynecol Endocrinol 32, 177-183, 2016.

Zuo T, Zhu M, Xu W. Roles of oxidative stress in Polycystic Ovary Syndrome and cancers. Oxid Med Cell Longev 2016, 8589318, 2016. 